\title{
A EVOLUÇÃO DO PEACEKEEPING: SUEZ, RUANDA E REPÚBLICA DEMOCRÁTICA DO CONGO
}

\author{
Maria Fernanda Affonso Leal ${ }^{1}$ \\ Rafael Santin ${ }^{2}$ \\ David Almstadter de Magalhães ${ }^{3}$
}

\section{Introdução}

No dia 28 de março de 20I3, o Conselho de Segurança das Nações Unidas aprovou a Resolução 2098, por meio da qual estabeleceu a chamada Brigada de Intervenção na República Democrática do Congo com o objetivo de "neutralizar e desarmar" as milícias rebeldes no território congolês. Essa resolução tem sido considerada um marco na história das missões de paz da ONU, que desde seu início operam segundo o princípio do uso mínimo da força.

A criação da Organização das Nações Unidas, no pós-Segunda Guerra Mundial, tinha como objetivo evitar a deflagração de novos conflitos no sistema internacional por meio da cooperação entre os países membros. As missões de paz não foram mencionadas na Carta de fundação da ONU; no entanto, o Capítulo VI do documento trata da solução pacífica de controvérsias, e o Capítulo VII estabelece instrumentos pacíficos e não pacíficos de segurança coletiva com vistas a preservação da paz internacional.

Na década de I950, durante a crise de Suez, foi criada a primeira peacekeeping operation da ONU. Com o objetivo de não permitir que o confli-

I Bacharel em Relações Internacionais pela Universidade Anhembi Morumbi. E-mail: fernandaaffonso.1@gmail.com

2 Bacharel em Relações Internacionais pela Universidade Anhembi Morumbi. E-mail: rafasantingo@gmail.com

3 Professor de Relações Internacionas da FAAP e da Universidade Anhembi Morumbi. E-mail: david.dvdmg@gmail.com 
to escalasse de maneira incontrolável a Assembleia Geral decidiu enviar um contingente militar para manter a paz na região. Essa primeira tentativa foi avaliada como bem sucedida pela ONU.

Desde então, a ONU se envolveu em inúmeros conflitos ao redor do mundo, na maioria das vezes observando as premissas básicas das operações de manutenção da paz: uso mínimo da força, imparcialidade e consentimento. Essas características são consideradas a base desse tipo de missão, pois sem elas as intervenções da ONU seriam consideradas beligerantes, e consequentemente, uma parte ativa do conflito. Entretanto, em razão do fim dos impasses entre os membros do Conselho de Segurança, no pós-Guerra Fria houve uma mudança na abordagem das peacekeeping operations. O número de missões aumentou vertiginosamente, principalmente devido às inúmeras guerras civis que proliferaram nessa época.

Em sintonia com essa maio $r$ participação da ONU em conflitos internacionais, Boutros Boutros-Ghali, Secretário Geral (SG) em I992, lançou a Agenda for Peace, um documento que estabeleceu as bases das peacebuilding operations ${ }^{4}$. Essas operações visavam construir uma paz duradoura, que seria alcançada através do desenvolvimento da capacidade administrativa dos Estados em guerra. Isso tornou o envolvimento da ONU nesses Estados mais complexo e, consequentemente, mais dispendioso.

Durante a década de I990, quando a ONU enfrentou sérios problemas com relação às missões de paz, a sua postura errática e hesitante tornou-se um marco na história da Organização. Kofi Annan, que à época da missão em Ruanda estava à frente do Department of Peace Keeping Operations (DPKO), presenciou as dificuldades enfrentadas pela United Nations Assistance Mission for Rwanda (UNAMIR) em razão das restrições impostas pelo Conselho de Segurança com relação ao modus operandi da missão. Portanto, por conta de sua experiência, quando assumiu o cargo de Secretário Geral da ONU, Kofi Annan convocou o Painel sobre as Missões de Paz da ONU com o objetivo de avaliar as deficiências do sistema de missões de paz que foi empregado até aquele momento.

Deste painel resultou o Relatório de Brahimi, que estabeleceu um novo comprometimento dos países membros, além de mudanças institucionais significativas e o aumento do apoio financeiro às missões de paz, tornando-se um ponto de inflexão no processo de releitura da ONU em relação aos

4 O documento também definiu as operações de peace enforcement como sendo unidades dos Estados-membros formadas por tropas voluntárias, além de contarem com armamentos mais pesados que as missões de peacekeeping. O estabelecimento destas tropas é autorizado pelo Conselho de Segurança e, como no caso das operações de paz, também ficam sob o comando do Secretário Geral (ONU, I992). 
seus instrumentos de intervenção humanitária.

Em 2013 ocorreu a mudança mais significativa no procedimento das peacekeeping operations: a criação da Brigada de Intervenção para a Mission de l'Organisation des Nations Unies pour la Stabilisation en RD Congo (MONUSCO), a missão de paz da ONU na República Democrática do Congo. A Brigada de Intervenção também está atada aos princípios básicos das peacekeeping operations - consentimento, imparcialidade e uso mínimo da força. Essa obrigatoriedade em seguir com os princípios surgiu da preocupação da organização de que o novo rule of engagement da Brigada pudesse deslegitimar a base das operações de paz. Apesar da estreita ligação com as peacekeeping operations, a Brigada de Intervenção é, segundo o Secretário Geral, a primeira força de combate ofensiva criada para controlar as ondas de violência na RDC (Fett 2013).

Levando em consideração as questões legais e possíveis controvérsias causadas pela criação da Brigada de Intervenção, podemos avaliar o surgimento desta como um passo em direção a uma nova forma de encarar as missões de paz. Torna-se pertinente indagarmos: estamos diante de um momento de mudança na abordagem das missões de paz da ONU?

A hipótese deste artigo desenvolve-se a partir do princípio de que após os sucessivos fracassos em suas intervenções, que culminaram, por exemplo, no famigerado genocídio em Ruanda de I994, a ONU - ou mais especificamente o Conselho de Segurança - passou a implementar uma série de mudanças com o intuito de reparar alguns equívocos experimentados nas peacekeeping operations. Por meio da análise da evolução das operações de paz, e utilizando como parâmetros de comparação as operações UNEF I (Canal de Suez), UNAMIR (Ruanda) e MONUSCO (RDC), serão analisadas as mudanças no modus operandi da ONU para lidar com crises humanitárias.

\section{UNEF I: 0 primeiro passo da ONU}

Quando as missões de paz foram concebidas pela ONU no final da década de I940, o objetivo delas era ser uma força neutra interposta entre dois Estados em guerra após o estabelecimento de um cessar-fogo. A primeira missão a ser autorizada pelo Conselho de Segurança (CSNU) foi a UN Truce Supervision Organization (UNTSO) em I948, que tinha por objetivo monitorar o Acordo de Armistício feito entre Israel e os países árabes vizinhos e continua ativa até hoje (ONU, sem data).

Após a nacionalização da Suez Canal Company pelo governo egípcio, França e Reino Unido pediram uma reunião do Conselho de Segurança para 
discutir a situação. Após os pedidos, o CSNU se reuniu em setembro para decidir as ações que seriam tomadas com relação às questões recebidas. A resolução II8 (I956) foi adotada pelo CSNU, e o SG afirmou que faria o possível para fazer um acordo que fosse baseado nos princípios aprovados pelo Conselho (idem).

Porém, em outubro de 1956, a situação entre Israel e Egito tornou-se crítica quando o General Armistice Agreement celebrado entre os dois países foi desfeito por conta da invasão israelense - auxiliada por forças britânicas e francesas - ao território egípcio. Apesar das tentativas do Tenente-General E.L.M. Burns do Canadá - que estava à frente da UNTSO - de alcançar um cessar-fogo entre os países, o Egito foi bombardeado pela Inglaterra e França (ONU, sem data).

Em primeiro de novembro de 1956 a Assembleia Geral teve a sua primeira sessão emergencial para lidar com a situação no Oriente Médio, após o CSNU ter sido incapaz de chegar a um acordo por conta dos vetos dados pela França e Reino Unido. A Assembleia aprovou a resolução 997 (ES-I) que pedia um cessar-fogo imediato, a retirada das forças e a reabertura do Canal. O Canadá absteve-se da votação, e Lester Pearson 5 justificou a escolha de seu país afirmando que era necessário tomar ações mais drásticas para auxiliar o cessar-fogo na região. Pearson sugeriu que fosse instalada uma força policial das Nações Unidas que pudesse auxiliar a resolver a crise; e em discussões com o Secretário Geral chegaram à United Nations Emergency Force (UNEF), a primeira missão de paz armada da ONU (ibidem).

A sugestão do Canadá foi aprovada na resolução 998 (ES-I) de 4 de novembro de 1956 , e no mesmo dia o SG encaminhou o primeiro relatório com o plano para a força emergencial das Nações Unidas. No segundo relatório do SG, do dia 6 de novembro, ele definiu o conceito da nova força e os princípios que deveriam guiá-la durante o seu mandato, entre eles um que seria fundamental para as missões futuras: que a missão não teria direitos além do necessário para a execução de suas funções, que esta seria mais do que uma missão de observação, mas de maneira alguma, seria uma força militar controlando o território (ONU, sem data)

A Assembleia Geral aprovou um total de sete resoluções durante a sessão especial de emergência; essas resoluções formaram a UNEF I, e deram ao SG a autoridade e o apoio necessários para colocar um fim às disputas entre Egito e Israel. A UNEF I marcou o surgimento das missões de paz armadas da ONU, que a partir desse momento seriam cruciais para a manutenção

5 Conselheiro da delegação do Canadá na ONU, Presidente da sétima sessão da Assembleia Geral e Primeiro Ministro do Canadá. 
da paz no sistema internacional. Porém, para que a Força pudesse atuar em território egípcio, era necessário que o governo do país desse seu consentimento; sendo este um ponto fundamental para a implementação da UNEF I e continua como um princípio das missões de paz até hoje.

As negociações para o cessar-fogo e a retirada das tropas das fronteiras foram feitas pelo próprio SG, através de resoluções adotadas pela Assembleia Geral e discussões com os governos dos países envolvidos. Isso facilitou a ação da UNEF I em campo, que deveria apenas apoiar as decisões tomadas anteriormente, e auxiliar nos processos de paz.

A missão foi implementada em quatro fases, sendo elas: de novembro a dezembro de 1956 com o objetivo de auxiliar a retirada das tropas britânicas e francesas da área do Porto Said; a segunda começou do final de dezembro de 1956 e estendeu até março de 1957 observando a retirada das forças israelenses da Península do Sinai; a terceira fase da UNEF I focou na retirada das tropas de Israel dessas duas áreas; e a última fase envolveu a distribuição das tropas da UNEF I ao longo da fronteira entre Egito e Israel, e durou aproximadamente Io anos, de março de I957 a maio de I967. (ONU sem data).

Em I967 a situação na fronteira Israel-Egito estava estável por conta da ação da missão de paz na região; porém, as fronteiras de Israel com a Síria e Jordânia apresentavam constantes problemas. Quando as forças sírias e israelenses trocaram tiros em sua fronteira, o governo egípcio pediu para que a UNEF I se retirasse de seu território, afirmando que esta já havia terminado suas funções na região. O Secretário Geral aceitou os termos egípcios, uma vez que o consentimento do governo necessário para manter as tropas no país havia sido retirado (ibidem).

Quando a UNEF I surgiu, as características do sistema internacional eram bem delineadas: o contexto era de Guerra Fria e de conflitos predominantemente estatais. Isso facilitou a implementação de uma missão para interpor-se entre Estados em guerra, pois as negociações de cessar-fogo e retirada de tropas eram feitas no âmbito da ONU, sendo regidas pelo próprio SG em conversas com os representantes dos Estados envolvidos. Uma vez que um acordo tivesse sido alcançado, o FC da UNEF I levaria as ordens aos comandantes militares em campo, e lá eles organizariam como se daria a retirada das tropas.

A UNEF I sendo a primeira missão de paz armada da ONU abriu precedentes para todas as que viriam; por isso as bases desta são utilizadas até hoje; e seus conceitos são fundamentais para o estabelecimento de todas as missões de paz das Nações Unidas. Este modelo, no entanto, sofreu poucas alterações para adaptar-se ao novo contexto internacional. Tal rigidez com relação ao modus operandi eventualmente trouxe complicações para a ONU, 
que precisou lidar com situações muito diferentes daquela que deu início às missões, utilizando o mesmo modelo. Apesar disso, a UNEF I é considerada pela ONU uma das missões mais bem sucedidas da história da organização, pois conseguiu colocar fim a uma guerra e trouxe io anos de paz a uma região extremamente instável.

\section{UNAMIR: Os equívocos da ONU em Ruanda}

Entre as décadas de i980 e I990 é possível perceber o surgimento de novos tipos de conflitos, diferentes daqueles ocorridos até então. Esses conflitos foram denominados "novas guerras" por Mary Kaldor (I999), e diferem das guerras antigas em alguns pontos cruciais. Marcadas principalmente por conflitos civis, as novas guerras são uma herança da Guerra Fria e dos "vácuos de poder" que aparecem tipicamente em períodos de transição, e normalmente ocorrem em países que sofrem com corrupção governamental e com o declínio da economia. Tais elementos criam um cenário propício para o surgimento de grupos paramilitares, crime organizado e a violação dos direitos humanos em larga escala. (Kaldor idem).

Apesar do surgimento deste novo tipo de violência organizada no período pós Guerra Fria, defende a autora, as novas guerras não suplantaram os conflitos interestatais, isto é, o que ela denomina de "velhas guerras". Os conflitos contemporâneos ganharam mais complexidade, pois há uma convivência, potencializada pela globalização, entre atores estatais e atores não-estatais, entre o governamental e o transnacional.

As novas guerras estão concentradas principalmente na África, Leste Europeu e Ásia, lugares em que os fatores supracitados estão claramente presentes. Se avaliarmos a situação de Ruanda, poderemos notar que além de ser um país desigual e corrupto, facções inimigas permeiam seu território e, de acordo com Kaldor (1999), têm o objetivo comum de semear o medo e o ódio na população, de modo a ganhar o controle desta e consequentemente, ter mais poder. Para Kaldor (idem), as novas guerras precisam ser compreendidas dentro do contexto da globalização, ou seja, de intensificação das conexões globais. Uma das consequências deste processo de globalização é a disseminação de ideais, como por exemplo, a onda de democratização dos anos I990, subsequente ao final da Guerra Fria.

Esse processo de democratização é apontado por Filip Reyntjens (I996) como um dos fatores cruciais para a eclosão de violência em Ruanda no início dos anos 90. Na época, o presidente Juvénal Habyarimana buscava adaptar-se à onda internacional, e criou em 1990 a 'National Synthesis Com- 
mission on Political Reform' com a intenção de democratizar o país. Logo após a criação da Comissão, a Frente Patriótica Ruandesa (RPF - Rwandese Patriotic Front) invadiu a capital do país e deu início a uma guerra contra o governo central hutu. De acordo com Reyntjens, essa invasão foi planejada pela RPF de maneira a desestabilizar ainda mais o país em um momento em que o governo buscava se democratizar. Assim, uma vez que Habyarimana deixasse de ser considerado um ditador, a RPF perderia um de seus argumentos mais fortes: a luta contra uma ditadura monolítica (Prunier I993, I30).

A onda de violência que assaltou Ruanda em 1994 começou a partir de I99I na forma de ataques pontuais e planejados, perpetrados pelos 'esquadrões da morte' ligados ao governo - e à família - de Habyarimana. Os ataques tinham como objetivo sabotar as negociações para o Acordo de Paz de Arusha e, também, o processo de democratização (Reyntjiens I994). Neste contexto turbulento, o Acordo de Paz foi assinado em 4 de agosto de I993, apesar das tentativas de sabotagem vindas da ala mais radical do regime de Habyarimana.

O acordo de Arusha estabelecia um amplo papel para a chamada Força Neutra Internacional (NIF) - que seria disponibilizada pela ONU na forma da United Nations Assistance Mission for Rwanda (UNAMIR) - durante o período de transição pós-assinatura, que deveria durar 22 meses. A força teria papel fundamental na segurança do país durante o período de seu mandato. Constavam entre suas atribuições: garantir a segurança do país, mantendo a lei e a ordem; garantir que a ajuda humanitária chegasse a todos em segurança e auxiliar na proteção dos civis. Além disso, a força deveria auxiliar na localização de depósitos de armas, na neutralização de gangues armadas e na recuperação de armas distribuídas ou adquiridas ilegalmente pelos civis (ONU i999).

Em agosto de I993, uma missão de reconhecimento foi despachada para Ruanda com o Tenente-General canadense Roméo A. Dallaire no comando. Esta deveria avaliar as possíveis funções da NIF e os recursos necessários para estabelecer a missão de paz. O Conselho de Segurança aprovou unanimemente o estabelecimento da UNAMIR, mas com algumas ressalvas, a mais marcante sendo a ausência da sugestão de que a UNAMIR auxiliasse na recuperação de armas adquiridas ilegalmente (ONU I999).

Em outubro de I993, a UNAMIR foi estabelecida em solo ruandês. O escolhido para ser o Force Commander (FC) da UNAMIR foi o próprio Dallaire, que ficou à frente da missão de outubro de I993 a agosto de I994. Como Representante Especial do Secretário Geral (SRSG), o SG Boutros Boutros Ghali apontou o ministro das relações exteriores de Camarões e seu amigo, Sr. Jacques-Roger Booh Booh, que chegou a Kigali em novembro de I993. 
Em novembro de I993, Dallaire enviou um rascunho do Rules of Engagement (ROE) para a UNAMIR à sede da ONU em Nova York para aprovação do secretariado. Neste rascunho, ele pedia especificamente para que a UNAMIR pudesse agir e fazer uso da força como resposta a crimes contra a humanidade e outros abusos. De acordo com o relatório de I999 da ONU com relação a Ruanda e com o próprio Dallaire (2003), este rascunho feito pelo FC nunca teve uma resposta formal vinda da sede 6 .

Um dos exemplos mais marcantes da inflexibilidade da ONU com relação ao ROE estabelecido foi o caso do telegrama enviado por Dallaire no dia II de janeiro pedindo à ONU a retirada de um informante do território ruandês. Este, um importante membro da Interahamwe - a milícia extremista de Ruanda - relatou evidências sobre a existência de depósitos de armas que poderiam vir a ser utilizadas para o massacre.

Dallaire indicou que suas tropas estavam prontas para ir até os depósitos fazer um reconhecimento dentro das próximas 36 horas, e recomendava que o informante recebesse proteção e fosse retirado do país. A sede negou o pedido para levar a operação adiante, e instruiu Dallaire e Booh Booh a pedir uma reunião urgente com o Presidente Habyarimana para deixá-lo a par das informações recebidas sobre a Interahamwe e como estas poderiam afetar o estabelecimento da paz (ONU I999).

Essa decisão tomada pela ONU foi ancorada nas diretrizes sobre Missões de Paz do Capítulo VI, que estabelecem o consentimento do Estado para as forças das Nações Unidas poderem agir. Porém, como veio a se provar posteriormente, o presidente estava envolvido com o massacre e não tinha interesse em manter a paz; dessa forma, quando o FC informou Habyarimana sobre a localização das armas e pediu que o presidente tomasse ações efetivas contra a Interahamwe, o que o chefe de estado fez foi realocar as armas e permitir que o massacre continuasse como planejado.

Em 30 de março de I994, o Secretário Geral, Boutros Boutros Ghali, apresentou um relatório sobre o desempenho da UNAMIR para o Conselho de Segurança, e sugeriu que o mandato desta fosse estendido em mais seis meses. Os membros do CSNU demonstraram incrível relutância em aceitar o prolongamento da missão, e, consequentemente, uma extensão de pouco menos de quatro meses foi aprovada pelo CSNU em cinco de abril. A resolução 909 (I994) incluía também a possibilidade de aumentar este período caso o processo de paz não demonstrasse progresso durante o tempo estabelecido.

A onda de violência em Ruanda escalou vertiginosamente após o as-

6 A ROE foi a precursora das mudanças vistas posteriormente na missão da República Democrática do Congo. 
sassinato do presidente Habyarimana, que voltava de uma reunião sobre os acordos de Arusha na Tanzânia, juntamente com o presidente do Burundi, Cyprien Ntaryamira, em seis de abril de I994. O avião em que ambos estavam sofreu um atentado quando se aproximava do aeroporto de Kigali. Pouco após a explosão, a Guarda Presidencial instalou bloqueios nas estradas com o auxílio da Interahamwe. Os militares rapidamente tomaram o comando do país, dispensando a autoridade da Primeira-Ministra, Sra. Agathe Uwilingiyimana (ONU I999).

O FC mandou um relatório para a sede informando que a UNAMIR talvez precisasse usar força para resgatar a Primeira-Ministra, ao qual Iqbal Riza - do DPKO - respondeu confirmando a ROE aprovada: que a UNAMIR só deveria atirar se sofressem o ataque primeiro (idem). Dessa forma, os soldados belgas postados à frente da casa da Primeira-Ministra acabaram entregando as armas à Guarda Presidencial e subseqüentemente foram levados ao Campo Kigali, onde sofreram diversas agressões e foram mortos.

O FC deixou claro que uma operação para resgatar os soldados do Campo Kigali não era viável por conta dos riscos em que seria colocada a equipe de resgate, e pelas grandes chances da missão falhar. Ele afirma que como não tinha o poder de fogo necessário para atacar as tropas da RGF, um resgate seria algo irresponsável. Dallaire também compreendia que atacar o complexo da RGF os tornaria alvos legítimos e consequentemente, um terceiro beligerante.

Em um relatório para a comissão do senado belga, Dallaire descreveu as deficiências da UNAMIR e sua falta de recursos: "A UNAMIR era uma operação de peacekeeping. Não estava equipada ou treinada para conduzir uma operação de intervenção" (ONU I999. Tradução nossa). Nas palavras do FC vemos a inadequação de uma missão de paz clássica para a situação de Ruanda, que lidava com beligerantes de um mesmo Estado e uma guerra civil e não mais com guerras entre Estados como na época da Guerra Fria. As restrições desse tipo de missão e do ROE levaram à morte desnecessária de dez soldados belgas, que poderiam ter se defendido se tivessem permissão para abrir fogo quando fossem ameaçados:

Nós estávamos mandando nossos soldados, que estavam preparados para uma missão de paz clássica do Capítulo Seis, para um mundo que parecia cada vez menos receptivo a esse tipo de intervenção. (Dallaire 2003, 40,4I. Tradução nossa)

Antes de a UNAMIR começar seu mandato, Roméo Dallaire já compreendia que a missão necessitava de um poder maior do que o que fora esta- 
belecido, e que sem isso, as chances de fracasso seriam grandes. Após a morte dos soldados belgas, a missão tomou mais um baque da qual não conseguiria se recuperar; o primeiro-ministro da Bélgica, Willy Claes, pediu ao Secretário Geral que as operações da UNAMIR fossem suspensas, por não ter sido bem sucedida em manter a paz e evitar as mortes que tinham ocorrido até o momento. O CSNU não autorizou a suspensão da missão, o que levou a Bélgica a retirar suas tropas do solo ruandês, desfalcando a UNAMIR de seus soldados mais bem equipados e treinados.

A retirada da Bélgica levou a uma discussão dentro da sede da ONU sobre o mandato da UNAMIR e se esta deveria ser mantida com um contingente bem menor, ou se ela deveria ser suspensa. Em 2i de abril de I994, o CSNU aprovou a resolução 9I2 (I994) que reduzia o contingente da missão para apenas 270 tropas e mudava o mandato desta. Porém, abril foi o mês em que Ruanda presenciou a pior onda de massacres em seu território; até o final do mês aproximadamente 200.000 ruandeses haviam sido mortos. Essa situação modificou a perspectiva do Secretário Geral, que enviou uma recomendação ao CSNU, pedindo que a decisão de diminuir a força da UNAMIR fosse revertida. De acordo com Boutros Ghali, a resolução 9 I2 (I994) não dava à missão a capacidade de tomar ações efetivas contra o massacre que acontecia (ONU I999). Para o Secretário Geral o CSNU precisava considerar que ações poderiam ser tomadas para restaurar a lei e a ordem. Essas ações demandariam recursos materiais e contingentes em uma escala que os Estados Membros até o momento se mostraram relutantes a contemplar (ibidem).

Essa mudança de posicionamento do Secretário-Geral exemplifica a falta de direção e mesmo interesse que a sede da ONU demonstrava em relação ao caso de Ruanda. As decisões eram tomadas baseadas nos gastos que os países teriam ao auxiliar a missão, não no que seria mais eficiente e para evitar o massacre. Um dos problemas enfrentados pela UNAMIR com relação ao seu mandato eram as ordens contraditórias vindas da sede, que por vezes falhava ao passar informações.

Em meados de maio de I994, o Secretário- Geral enviou ao CSNU um relatório que descrevia a implementação da chamada "UNAMIR II" que deveria contar com uma força de 5.500 tropas. O novo mandato da UNAMIR levantou discussões dentro do CSNU, pois este estava dividido entre seus membros. Apesar das divergências, em I7 de maio de I994 a resolução 9I8 (I994) foi adotada pelo CSNU.

Para dar continuidade à resolução 9I8, o Secretário Geral enviou o General Maurice Baril - chefe da divisão militar do DPKO - e Iqbal Riza, também do DPKO, para avaliarem a situação em Ruanda e auxiliar os beligerantes a chegarem a um acordo sobre o cessar-fogo. O relatório enviado à base 
reconhecia que tentar estabelecer um cessar-fogo sem tentar parar os massacres não seria aconselhável, pois se os massacres continuassem poderiam levar a um ciclo de violência prolongado, por isso parar as mortes deveria ser algo concomitante ao cessar-fogo (Dallaire 2003).

A partir das informações enviadas por Baril e Riza, o Secretário Geral formulou um relatório que foi enviado ao CSNU no dia 3i de maio. Nele foi incluída uma retrospectiva das informações sobre a situação em Ruanda que o Secretariado já tinha acesso antes do início do genocídio, ou seja, provava que o CSNU tinha o conhecimento e a capacidade de ter evitado os massacres subseqüentes, porém não tomou as ações necessárias para isso. O relatório também dava as diretrizes para a implementação da UNAMIR II com um mandato maior do que seu predecessor, que incluía prover a segurança de civis que estivessem sob ameaça e também para as operações humanitárias.

Esse relatório foi de extrema importância para ressaltar os problemas inerentes à ONU e ao CSNU, que por questões geopolíticas e orçamentais, muitas vezes evitam tomar ações que possam poupar vidas. Foi um primeiro passo em direção a uma nova forma de lidar com as missões de paz, pois se começou a perceber que os mandatos estabelecidos eram inadequados às situações apresentadas e por isso muitas vezes, os agentes ficavam atados a regras desatualizadas que prejudicavam tanto as missões quanto os civis dos países afetados.

Em uma tentativa de controlar a situação em Ruanda, o Secretário-Geral sugeriu ao CSNU a adoção da chamada "Operação Turquesa" que foi oferecida pela França. O plano era uma conduzir uma operação de peace enforcement multinacional baseada no Capítulo VII da Carta da ONU - que prevê intervenções militares em outros países - para assegurar a proteção e a segurança dos refugiados e civis que estivessem em risco em Ruanda (ONU I999). No final de junho de I994, essa operação foi estabelecida para auxiliar a UNAMIR a controlar a situação.

O FC da UNAMIR era contra a operação desde o início, pois sabia os riscos que isso poderia trazer para a missão de paz que ainda estava em seu mandato. Uma de suas maiores preocupações era com as tropas da UNAMIR que fossem da mesma nacionalidade daquelas participando da Operação Turquesa. Isso era fundamental, pois a Operação Turquesa tinha carta livre para o uso da força, sendo considerada beligerante, ao contrário da UNAMIR.

Apesar da contestação de Dallaire, a operação seguiu em frente e se estabeleceu principalmente na fronteira de Ruanda com o antigo Zaire. Em meados de julho de I994, a situação dos refugiados tornou-se emergencial, com mais de um milhão de ruandeses cruzando a fronteira entre os dois países. A situação dos refugiados era de extrema importância, pois quanto maior 
o número de ruandeses entrando no Zaire, mais instável se tornava a situação do país. Os franceses da Operação Turquesa e os zairianos estavam desarmando os soldados da RGF que tentavam entrar no país, porém nas palavras de Dallaire "nem os zairianos nem os franceses estavam tomando as medidas necessárias para separar a milícia, gendarmes ou soldados dos civis quando estes cruzavam a fronteira" (2003, 47I. Tradução nossa). Isso se mostrou ter sido um erro fundamental no acolhimento dos refugiados, pois permitiu que os soldados ruandeses se fortalecessem novamente dentro do Zaire, levando o país a uma reviravolta política que foi, inevitavelmente, conseqüência da situação em Ruanda7.

Em i8 de julho a RPF já havia tomado conta de todo o território ruandês, com exceção da zona controlada pela Operação Turquesa e declarou um cessar-fogo unilateral, colocando fim aos cem dias de massacre em Ruanda. No dia seguinte um governo provisório foi estabelecido, com Pasteur Bizimungu $^{8}$ na presidência e Paul Kagame ${ }^{9}$ como vice-presidente. Com esse novo governo surgiram as promessas de um país melhor, mas ainda sem falar em reconciliação entre hutus e tutsis.

A situação em Ruanda foi resultado de uma junção de fatores, entre eles salientamos aqui as ações da ONU, que foi incapaz de agir rapidamente para evitar os massacres e acabou por levar essa mancha em sua história. O relatório feito em I999 pelo Secretário Geral levantou questões fundamentais para compreender como a inação da ONU afetou Ruanda; no final do relatório, o SG enumera os erros cometidos tanto pela Organização no geral, quanto pelo CSNU, sendo este essencial para que no futuro as decisões tomadas sejam mais conscientes das possíveis consequências, evitando que essa situação torne a acontecer. Concluímos desta forma, que o massacre de Ruanda foi um passo importante para que começassem a ocorrer mudanças no modo como as missões de paz são estabelecidas, principalmente em países que sofrem com conflitos internos e não têm capacidade para receber uma missão de paz que esteja atada aos três princípios básicos: consentimento, mínimo uso da força e imparcialidade.

\section{MONUSCO}

7 Além desta falha no controle da fronteira, a zona estabelecida pela Operação Turquesa provou-se propícia para que a Interahamwe continuasse com o massacre sem que os soldados franceses interviessem. Ademais, a Operação protegeu membros extremistas do governo contra a RPF, que os levaria para julgamento, e ajudou-os a fugir do país (The Guardian 2007).

8 Conselheiro político sênior da RPF, membro do Comitê Executivo da RPF, hutu.

9 Comandante militar do Rwandese Patriotic Army, a ala militar da RPF, tutsi. 
A experiência em Ruanda mostrou que o formato das missões de paz utilizado até o momento era inadequado às situações e aos conflitos da chamada Nova Ordem Mundial. Por conta disso, quando a missão na República Democrática do Congo foi implementada, o CSNU buscou fazer alterações fundamentais na estrutura da operação, inaugurando uma nova etapa nas operações de paz da ONU. A MONUSCO foi um ponto de inflexão importante, principalmente por conta do conflito deflagrado na RDC ter sido uma consequência direta da situação em Ruanda.

Após a assinatura do Acordo de Lusaka, a ONU autorizou o estabelecimento de uma missão de paz na RDC, e em novembro de I999 foi criada a MONUC. O mandato original da missão incluía tarefas de observação e assistência, que não envolviam o uso da força, e o CSNU evitou, em um primeiro momento, fazer menção a ameaças à segurança e à paz internacional (Janik 20I4). Porém, em 2000, a violência escalou rapidamente, levando o CSNU a declarar que a situação na RDC colocava em perigo a paz internacional. O resultado desse novo entendimento foi a aprovação da histórica Resolução I29I, a qual autorizou a MONUC a empregar a força quando necessário para proteger o staff da ONU e da Joint Military Commission (JMC) $)^{\mathrm{IO}}$ e civis de ataques e ameaças iminentes (Janik 20I4).

As hostilidades constantes impediam que a MONUC exercesse as tarefas de observação e monitoramento. Os inúmeros grupos militares presentes na RDC levaram a uma fragmentação territorial do país, causando uma sensível piora na situação humanitária, com centenas de milhares de vítimas e pelo menos dois milhões de refugiados (JANIK, idem). Em resposta a essa situação, o CSNU aprovou em 2003, uma intervenção liderada pela França, para controlar a onda de genocídios na região nordeste do país. A Resolução também autorizava a MONUC a auxiliar o governo nos esforços de desarmamento das milícias.

A Resolução 1565 de 2004 autorizou uma missão multidimensional de peace enforcement e peace building, que estava de acordo com os padrões estabelecidos pelo Relatório Brahimi de 2000 (ibidem) ${ }^{\text {II }}$. É possível que o novo

Io Composta pelos beligerantes e estabelecida pelo Acordo de Lusaka, para investigar violações do cessar-fogo e desarmar milícias.

II O Relatório estabeleceu novos parâmetros principalmente para as missões que envolvem peace building e peace enforcement, entre eles: a inclusão de programas de desmobilização e reintegração no orçamento da primeira fase das missões de paz complexas; a criação de um plano para fortalecer a capacidade permanente da ONU para desenvolver estratégias de peace building; além de enfatizar a importância de os peacekeepers serem capazes de se defender, cumprirem seus mandatos de maneira profissional e bem-sucedida, utilizando rules of engagement 
mandato da MONUC tenha ido muito longe ao permitir um papel tão ativo das forças internacionais, e consequentemente, questionando a capacidade do governo central da RDC de lidar com a questão. Isso levou o presidente Kabila a tentar retirar qualquer influência internacional, e anunciou publicamente a intenção de ver a MONUC sair do país até o verão de 20II. Por conta disso, em julho de 20I0, a Resolução I925 renomeou a missão para MONUSCO, de modo a enfatizar os importantes passos que estavam dando em direção à paz (ibidem).

A utilização do peace enforcement dentro de uma missão de paz não foi uma novidade trazida exclusivamente para a MONUC, uma vez que outras operações de paz já fizeram uso do Capítulo VII para alguns ou todos os aspectos de sua missão. Já nos anos I960 a United Nations Operation in the Congo (ONUC) foi autorizada a utilizar a força, se necessário, para evitar a deflagração de uma guerra civil no país. Outro exemplo da utilização da força no mandato ocorreu durante a década de 1990 com a United Nations Operation in Somalia II (UNOSOM II) que teve um mandato de enforcement aprovado para poder estabelecer áreas seguras para assistência humanitária dentro do território somali (Boulden 200I). Entretanto, como assinala Boulden (idem), embora tenha havido tentativas de enforcement anteriores à MONUC, elas não lograram êxito. "Foi com otimismo predominante no pós Guerra Fria que a comunidade internacional encontrou horizontes para novos arranjos de segurança" (Boulden, idem, 9-I4).

Em $\mathrm{I}^{\mathrm{o}}$ de julho de 2oro, para marcar o início de uma nova fase na RDC, a MONUC foi renomeada MONUSCO (United Nations Organization Stabilization Mission in the Democratic Republic of the Congo) por meio da resolução I925. Entende-se por "nova fase", um progresso significativo da missão, como a consolidação de instituições do governo, a realização de eleições relativamente livres e transparentes, a estabilização da situação em boa parte do território, mas com a persistência do conflito e da crise humanitária no leste do país (ONU 20Io).

Dentre as mudanças previstas pela Resolução, há não só incrementos no contingente tanto de militares quanto de civis da missão, como também alterações em suas diretrizes. Destas, uma pode ser considerada a mais marcante para a missão, e que demonstra claramente uma tendência mais ofensiva em seu modus operandi:

[...] a proteção de civis deve ter prioridade em decisões sobre o uso de recursos e capacidade disponíveis e autoriza a MONUSCO a utilizar todos os meios necessários, dentro dos limites de sua capacidade e nas áreas onde

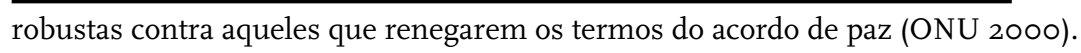


suas unidades estão estabelecidas, para realizar o seu mandado de proteção [...] (ONU 20Io. grifo nosso, tradução nossa)

Por mais que sua antecessora MONUC já tivesse bastante liberdade para agir e contasse com um contingente razoável de tropas, ao utilizar novamente o termo "all necessary means", o CSNU deixou clara a sua intenção de tornar a MONUSCO uma missão "robusta" desde sua criação, ao contrário da MONUC, que teve seu início como uma missão de paz que não fazia uso da força. Utilizando-se desse termo, são praticamente eliminados parâmetros para a missão no que se refere a meios a serem empregados para a proteção de civis, legitimando o uso da força em toda ação conduzida sob a égide da resolução.

Na resolução, temos o seguinte item entre as prioridades da missão:

Desenvolver e implementar, sempre consultando as autoridades congolesas e de acordo com a estratégia congolesa para reforma da justiça, um programa das Nações Unidas de apoio à justiça para desenvolver as áreas de justiça criminal, a polícia, o judiciário e prisões nas áreas afetadas pelo conflito. (ONU 20I0. Tradução nossa)

Portanto, ao colocar entre suas prioridades a reconstrução e o desenvolvimento de instituições como a polícia, e os sistemas judiciário e penitenciário, o CSNU estabelece o compromisso de estabilizar o Estado congolês por meio não só do combate a grupos armados e a violações dos direitos humanos, mas também da construção de uma estrutura burocrática com mecanismos que garantam o desenvolvimento de uma paz sustentável, de forma que o país possa com o tempo ter a autoridade necessária para controlar suas próprias crises.

Em junho de 20II, um ano após a Resolução que a implementou, a MONUSCO obteve resultados relevantes de uma forma geral no que diz respeito à paz e à segurança na RDC e na região dos Grandes Lagos como um todo (ONU 2OII). No entanto, ainda eram frequentes (principalmente no leste do país) conflitos armados e graves violações de direitos humanos, incluindo o recrutamento de crianças pelos grupos armados, execuções extrajudiciais e estupros em massa (ibidem). Fazendo então um apelo para que as partes envolvidas no conflito cessassem toda forma de violência e violação dos direitos humanos, o CSNU aprovou a extensão da MONUSCO por mais um ano por meio da Resolução I99I (Fett 20I3).

Outro elemento importante desta última resolução refere-se à renovação da importância atribuída às práticas de peacebuilding. O CSNU reconhece que, para a restauração da paz e a consolidação da democracia, por sua vez 
gerando desenvolvimento sócio econômico na RDC, seria necessária a realização de eleições transparentes e inclusivas no país. E assim declara que a MONUSCO apoiaria as eleições que seriam realizadas em novembro daquele ano por meio de suporte técnico e logístico (ONU 2OII).

Em meio a acusações de irregularidades nas eleições por observadores tanto nacionais quanto internacionais, Kabila foi reeleito presidente; e após três anos de pressão internacional, em março de 2012 finalmente ordenou a prisão do comandante de suas Forças Armadas, Bosco Ntaganda acusado de recrutar crianças para combate, estupro, assassinato e perseguição étnica, entre outras, tendo sido indiciado pela Corte Internacional em 2006 (ICG 20I2). O general então organizou um motim, e levando com ele parte das tropas formou o grupo rebelde Mouvement du 23-Mars (M23), que tomou a cidade de Goma e entrou em confronto direto com a FARDC e a MONUSCO, forçando centenas de milhares de pessoas a fugirem da região (ibidem).

Ao longo de 20I2, três resoluções foram aprovadas pelo CSNU, sendo suas temáticas principais a preocupação com o fluxo regional de recursos naturais que são utilizados pelos grupos rebeldes para sustentar seus arsenais, e a mais nova ameaça para a paz regional, o M23 (ONU 2OI2). O mandato da MONUSCO foi então estendido por mais um ano, e o CSNU anunciou que reforçaria a missão por meio da aplicação de novas sanções a países da região para coibir o tráfico de armas para os grupos rebeldes como o M23, que estava comprovadamente recebendo apoio do governo de Ruanda (BBC 20I3).

Depois de um período de batalhas intensas e tentativas de negociações entre o governo congolês e o M23, em fevereiro de 2013 eclodiu uma crise dentro do grupo rebelde que acabou por provocar uma divisão e consequentemente um conflito entre as duas facções que se formaram - um lado liderado por Bosco Ntaganda e o outro pelo coronel Sultani Makenga (ONU 2013). Apenas algumas semanas depois, a facção liderada por Ntaganda foi derrotada e o mesmo fugiu acompanhado de cerca de 600 de seus combatentes para Ruanda (ibidem). Para a surpresa de todos os envolvidos, em i8 de março Ntaganda se entregou à embaixada estadunidense em Kigali e pediu para que fosse transferido para o Tribunal Penal Internacional (BBC 20I5).

Finalmente, em 28 março de 20I3, por meio da Resolução 2098 o CSNU decidiu que para aumentar a eficiência da MONUSCO e dar uma solução definitiva para os ciclos recorrentes de conflitos e a violência em geral provocada pelos grupos armados presentes na RDC, deveria primeiramente abrir espaço para o processo de estabilização da região (ONU 20I3). Isto é, para que a missão pudesse garantir e manter a paz regional, primeiramente esta deveria ser conquistada por meio de ações estratégicas que contivessem os focos de violência. Assim, a MONUSCO não só foi estendida por mais um 
ano - até 3I de março de 2014 - como também passou a contar com uma Brigada de Intervenção (BI) dentre seus instrumentos. (idem).

\section{Brigada de Intervenção}

A Brigada de Intervenção foi incumbida de neutralizar grupos armados e desarmá-los de forma a facilitar as operações militares no contexto da missão e possibilitar o processo de estabilização do país. Contando com 3.069 homens distribuídos entre três batalhões de infantaria, um de artilharia, um de forças especiais e uma companhia de reconhecimento, a BI auxiliaria as autoridades da RDC em suas atividades por meio de operações ofensivas estratégicas "de uma forma robusta, extremamente dinâmica e versátil" (ONU 2013. Tradução nossa).

A Brigada de Intervenção foi estabelecida por conta de um contexto específico de conflitos na RDC, que por ter iniciado na década de I960, abrangeu tanto a Guerra Fria como o pós-guerra, permitindo a aplicação da definição de "nova guerra" estabelecida por Mary Kaldor (I999) e também a interpretação desta como uma guerra interestatal - devido à constante influência dos países vizinhos na RDC. Esse ambiente instável de conflitos entre grupos armados criou a necessidade de haver uma facção dentro da MONUSCO que fosse capaz de colocar um freio na violência gerada pelas milícias rebeldes e que tivesse o mandato específico para o uso da força ativamente.

É notável que, ao contrário do que ocorre nas Resoluções anteriores, logo nos primeiros parágrafos a Resolução 2098 contém uma série de ressalvas a respeito do conceito de peacekeeping, com o objetivo de assegurar os princípios que regem tais missões:

[...] Reafirmando os princípios básicos de operações de paz, incluindo o consentimento das partes, imparcialidade e o não uso da força, exceto em legítima defesa e defesa do mandato, e reconhecendo que o mandado de cada missão é específico às necessidades e à situação do país em questão. (Resolução 2098 20I3, I. Tradução nossa)

Dessa forma, o CSNU tentou deixar o mais claro possível que não pretende, com a introdução da BI, conduzir uma reforma na estrutura de suas missões de paz, mas apenas adequar a MONUSCO ao contexto em que está inserida. Não obstante, poderíamos afirmar que justamente essa repaginação dos princípios básicos de peacekeeping é um indício de que o CSNU percebe estar entrando em um novo território, como afirmou o embaixador britânico Mark Lyall Grant quando questionado sobre a introdução da BI (Al Jazeera 
20I3). Qualquer que tenha sido o objetivo do CSNU ao criar a BI pode-se afirmar que se trata da maior inovação no conjunto de práticas de peacekeeping dos últimos anos.

Outra preocupação presente na Resolução consiste em reforçar o respeito ao princípio da não-intervenção, numa tentativa de dissipar qualquer receio de que a BI pudesse representar uma ameaça à soberania da RDC ou de outros países da região (ONU 20I3. Tradução nossa): "reafirmando o seu comprometimento com a soberania, independência, unidade e integridade territorial da RDC e enfatizando a necessidade de respeitar os princípios da não-interferência, boa vizinhança e cooperação regional."

É necessário salientar que outra consequência importante da introdução da BI, e que foi apontada por Priscila Fett em seu artigo sobre a MONUSCO (Fett 20I3), refere-se ao status das forças de manutenção de paz em meio aos conflitos armados. Como explica Fett (idem), a ONU determinou por meio de um boletim ${ }^{\mathrm{I2}}$ do SGNU Kofi Annan (ONU I999) que apesar de seus peacekeepers serem obrigados a respeitar o Direito Internacional $\mathrm{Hu}$ manitário (DIH) ${ }^{13}$ quando utilizarem a força em legítima defesa, isso não os classificaria como combatentes, e portanto devem ter seu status equiparado ao de civis em conflitos armados nos moldes da IV Convenção de Genebra (CG I949). Entretanto, com as ações ofensivas agora empregadas pela BI, torna-se pertinente questionar se essas tropas podem ser consideradas como alvos legítimos na medida em que estão ativamente envolvidas nas hostilidades.

Ademais, é importante ressaltar que, ao contrário das missões com o mandato exclusivo de peace enforcement, a Brigada de Intervenção age completamente sob o consentimento do governo da RDC - as missões de peace enforcement buscam o consentimento do governo, se este existir, e são autorizadas a agir sem consentimento neste caso. E conforme afirma Fett (2013) não é possível estabelecer comparações entre a Brigada de Intervenção e a UNOSOM II e a Mission de Nations Unies pour la Stabilisation en Haiti (MINUSTAH), uma vez que a primeira não teve o consentimento do governo somali para usar a força, pois tinha o mandato de enforcement; e a segunda não previa ações ofensivas em seu mandato e era uma missão de estabilização em um país com níveis de violência inferiores àqueles encontrados na RDC.

Em novembro de 20I3, numa demonstração de sucesso na contenção

\footnotetext{
I2 O boletim intitulado Observance by United Nations Forces of International Humanitarian Law discorre sobre a necessidade de as tropas da ONU seguirem as normas do Direito Internacional dos Conflitos Armados (DICA). (ONU i999)

I3 O Direito Internacional Humanitário é um conjunto de normas que procura limitar os efeitos de conflitos armados. Protege as pessoas que não participam ou que deixaram de participar nas hostilidades, e restringe os meios e métodos de combate. (CICV I998)
} 
da crise na região, a FARDC - contando com o apoio da BI - finalmente derrotou os rebeldes do $\mathrm{M} 23$ (ONU 20I3). Apesar de a violência persistir na região com a resistência de grupos armados, principalmente a FDLR e as Allied Democratic Forces (ADF), a vitória sobre o M23 foi crucial, fazendo com que outros grupos passassem a se render e a demonstrar interesse em integrar a polícia e o exército congolês (ibidem). Em dezembro do mesmo ano, para oficializar o fim do M23, por meio da assinatura das chamadas Nairobi Declarations foram concluídas as negociações de Kampala' ${ }^{\mathrm{I4}}$ (SADC 2013).

Com o objetivo de preparar a FARDC para combater grupos rebeldes sem a necessidade de apoio de uma força estrangeira, a MONUSCO decidiu investir ainda mais na capacidade do exército congolês por meio do treinamento de suas tropas e da criação de equipes de treinamento para que estas possam perpetuar o conhecimento e a experiência adquiridos (ONU 20I3). E ainda nessa esteira, continuando com as práticas de statebuilding da missão, a MONUSCO auxiliou o governo no desenvolvimento e implementação de uma lei programática para a reforma da polícia entre 20I4 e $20 \mathrm{I7}$ (ONU 20I3).

Ao longo de 20I4, não foram observados avanços significativos na situação do leste da RDC, e o Final report of the Group of Experts on the Democratic Republic of the Congo (ONU 2015) reconheceu que o clima gerado pela derrota do $\mathrm{M} 23$ em novembro de 2013 não se traduziu em ganhos no que se refere à estabilidade da região. Grupos armados congoleses e estrangeiros como a FDLR, a ADF entre outros foram relativamente enfraquecidos, mas nenhum foi derrotado, tendo sido registrados diversos novos casos de abusos como torturas, violência sexual e massacres. Assim as duas Resoluções que foram aprovadas em 2014 mantiveram o arcabouço das anteriores, estendendo novamente o mandato da MONUSCO e sua Brigada de Intervenção por mais um ano, sem alterações significativas (ibidem).

Até a conclusão deste artigo, apesar de avanços significativos referentes tanto ao conflito no leste do país quanto à situação política da RDC, ainda eram recorrentes os relatos de violência. Foram registrados diversos novos casos de assassinatos, violência sexual, e sequestros, sendo talvez o evento mais trágico de 2015 a descoberta de uma vala comum contendo $42 \mathrm{I}$ corpos na região da capital Kinshasa (ONU 20I5). Os principais grupos armados FDLR, ADF e Lord's Resistance Army (LRA) - sofreram diversas perdas em ataques promovidos pelas FARDC com ou sem a parceria da $\mathrm{MONUSCO}^{15}$,

I4 Iniciadas em dezembro de 20I2, as chamadas Kampala Talks foram negociações ocorridas na capital de Uganda e facilitadas por seu presidente para se chegar a um acordo de paz entre a RDC e o M23 (SADC 20I3).

I5 A MONUSCO se recusou a auxiliar as FARDC em determinadas campanhas porque alguns dos generais congoleses estavam sendo acusados de violações de direitos humanos (ONU 
mas continuaram assolando o leste do país com ataques que deixaram aproximadamente 2,8 milhões de pessoas deslocadas em todo o território congolês (ibidem).

A última resolução aprovada para a MONUSCO aprovou sua prorrogação por mais um ano, até março de 2016 , apostando novamente na manutenção da Brigada de Intervenção. Essa resolução ordena ainda a redução de 2000 homens da força da missão, tendo em vista o progresso significativo que teria sido conseguido no que se refere às prioridades do mandato da MONUSCO, como a estabilização da crise e a proteção de civis (ibidem).

\section{Balanço das mudanças}

Para melhor entendermos mudanças nas missões de paz e, principalmente, as motivações que as ensejaram utilizaremos os parâmetros sugeridos de Duanne Bratt em seu trabalho Assessing the Success of UN Peacekeeping Operations (1996). Bratt apresenta quatro critérios para a avaliação do sucesso das missões de paz: desempenho do mandato, o auxílio na resolução do conflito, contenção do conflito e limitação do número de mortes.

O primeiro critério, desempenho de mandato, mede o grau de sucesso da missão ao avaliar o quão eficiente esta foi ao cumprir com o mandato estabelecido pelas resoluções do Conselho de Segurança (CSNU). De acordo com Bratt, esse critério é direto e relativamente simples de ser avaliado, porém não está isento de falhas.

O auxílio na resolução do conflito é um critério que indica se a missão foi capaz de facilitar a resolução das causas do conflito. É importante compreender que este indicador traz para a análise eventos que estão fora do controle da força da operação, pois apesar de os peacekeepers poderem auxiliar na resolução, essa só pode ser alcançada com a boa vontade dos combatentes.

O terceiro critério de avaliação é a capacidade de contenção de conflito da missão, ou seja, é determinado pela aptidão da missão em evitar a intervenção de potências ou Estados vizinhos no conflito. Mesmo se a intervenção for feita pela própria ONU, a missão será considerada um fracasso nesse critério pelo menos.

O último critério considerado por Bratt é a capacidade da missão em limitar o número de mortes durante o período em que esteve ativa. Para verificar o nível de sucesso da missão nesse indicador, é preciso comparar o

20I5). 
número de mortes - tanto militares quanto civis - antes e depois da atuação da missão no local.

A avaliação das missões, feita com base nos quatro fatores previamente apresentados, permite que elas sejam consideradas um sucesso, um sucesso moderado ou um fracasso. A tabela a seguir encaixa as três missões apresentadas neste artigo nas quatro categorias, avaliando o seu grau de sucesso.

\begin{tabular}{|c|c|c|c|c|c|}
\hline MISSÃO & $\begin{array}{l}\text { DESEMPENHO } \\
\text { DE MANDATO }\end{array}$ & $\begin{array}{l}\text { RESOLUÇÃO } \\
\text { DE CONFĹITO }\end{array}$ & $\begin{array}{l}\text { CONTENČÃO } \\
\text { DE CONFĹITO }\end{array}$ & $\begin{array}{l}\text { LIMITAC̣ÃO } \\
\text { NÚMERO DE } \\
\text { MORTES }\end{array}$ & BALANC̣O \\
\hline & & & & SUCESSO & \\
\hline UNAMIR & FRACASSO & FRACASSO & ERACACSO & FRACASSO & FRACASSO \\
\hline 1ONUSCO & & FRACASSO & & $\begin{array}{c}\text { NÃO } \\
\text { ANALISADO' }\end{array}$ & $\begin{array}{l}\text { SUCESSO } \\
\text { MODERADO }\end{array}$ \\
\hline
\end{tabular}

Nota ${ }^{16}$

As avaliações das missões deixam mais claro como a inadequação de um modus operandi pode influenciar negativamente o desenrolar de uma missão. A UNEF I foi uma missão bem sucedida, pois foi criada para a situação de conflito entre dois Estados e conseguiu seguir o mandato de maneira adequada. A UNAMIR, infelizmente, ainda seguia o mesmo modelo que a UNEF I, porém a situação era diferente, e isso afetou o resultado da missão em Ruanda, que não conseguiu controlar o conflito por não ter liberdade para agir quando necessário. No caso da MONUSCO, já podemos perceber tentativas da ONU para adequar o modus operandi da missão aos desafios que um conflito intraestatal apresenta, e consequentemente nota-se uma maior eficiência no caso da MONUSCO, principalmente quando comparada à UNAMIR.

\section{Considerações Finais}

O histórico das missões de paz permite uma análise profunda do desenvolvimento destas ao longo do tempo. Desde o seu início, as operações seguem impreterivelmente os três princípios que foram estabelecidos pelas Nações Unidas: imparcialidade, uso mínimo da força e consentimento. Estas

I6 Neste artigo consideramos o número de 5.4 milhões de mortos, por ser o mais usual, porém existem controvérsias com relação ao número. Em um relatório feito pelo International Rescue Committee (IRC) em 2007, foi afirmado que aproximadamente 5.4 milhões de pessoas morreram desde I998 na RDC, porém o número foi contestado em uma matéria de 2010 da World Politics Review, que afirma que este seria de aproximadamente 200.000 mortos por conta da guerra e que o número da IRC contabiliza as pessoas que morreriam mesmo em tempos de paz, ou seja, por conta de doenças e subnutrição. 
bases foram estabelecidas como uma maneira de controlar a atuação das tropas em campo e certificar-se de que a missão permaneça dentro das premissas do Capítulo VI da Carta da ONU.

Ao longo do período da Guerra Fria este modelo de missão de paz mostrou-se eficiente para interpor-se entre Estados beligerantes. Os conflitos deste período ocorriam principalmente entre dois ou mais países, o que facilitava a aplicação dos três princípios nas operações. Outro fator importante sobre os conflitos interestatais é que as negociações de um cessar-fogo podem ser feitas no âmbito da ONU, com a mediação do Secretário Geral. O fato de a ONU não ter adaptado o formato das missões de paz para as "novas guerras" mostrou-se prejudicial para o desempenho das operações, principalmente no início da década de I990.

A maior novidade nas missões de paz do pós-Guerra Fria foi a criação da Brigada de Intervenção para a MONUSCO. A BI é autorizada com base no Capítulo VII da Carta da ONU a promover operações ofensivas para neutralizar grupos armados sem a necessidade do consentimento das partes envolvidas no conflito (com exceção do governo congolês). Dito isso, podemos classificá-la como um instrumento de enforcement dentro de uma peacekeeping operation, o que por si só já evidencia a peculiaridade da MONUSCO.

É evidente que as crises internacionais têm características e origem próprias, e devem ter um tratamento especial, com missões de paz e seus mandatos desenvolvidos a partir de sua análise individual. Entretanto, certos aspectos estruturais fazem parte de qualquer missão, e apesar de a Brigada ser um instrumento exclusivo da MONUSCO, é possível que abra um precedente na medida em que cria um novo tipo de missão resultante do Capítulo VI com alguns aspectos do Capítulo VII da Carta da ONU, ou "Capítulo Seis e meio”, como disse o SG Dag Hammarskjöld (UNIS, sem data).

De acordo com Kenkel (2013), durante a sua progressão, as missões de paz evoluíram de suas posições reativas de paliativo para os conflitos, para posições proativas que buscam influenciar os resultados dos conflitos. Por isso, de uma forma geral, podemos apontar uma série de transformações que a princípio são consideradas pela ONU como de uso específico em determinadas missões, mas que se analisadas cronologicamente como feito no presente trabalho, tornam-se grandes mudanças estruturais nas missões de paz, reflexos da relativamente recente entrada da organização na ordem mundial pós-Guerra Fria e sua contínua adaptação à nova realidade de guerras intraestatais. 


\section{REFERÊNCIAS}

Autesserre, S. 2010. The trouble with the Congo: local violence and the failure of international peacebuilding, New York: Cambridge University Press, I42-I43.

Boulden, J. 200I. Peace enforcement: the United Nations experience in Congo, Somalia, and Bosnia. Westport: Praeger Publishers.

Bratt, D. I996. "Assessing the success of UN peacekeeping operations." IN: International Peacekeeping, London: Routledge, 3(4): 64-8I.

Dallaire, R. A. 2003. Shake Hands with the Devil: The Failure of Humanity in Rwanda. Cambridge: Da Capo Press.

Fett, P. 20I3. "Tudo de novo no front: MONUSCO, uma nova era nas peacekeeping operations?" Revista de Direito Internacional, Brasília: UniCEUB. IO(2): 169-183.

Henson, K. D. 20I4. Peacekeeping in the Congo, 1999-2001: Success or Failure? Tese - School of Advanced Military Studies (SAMS), Fort Leavenworth, Kansas.

Janik, R. 20I4. "Putting Security Council Resolution 2098 on the Democratic Republic of Congo in Context: The Long Way of Peacekeeping."10 Human Security Perspectives,I42-185.

Kaldor, M. I999 New and Old Wars : Organized Violence in a Global Era, Stanford: Stanford University Press.

Kenkel, K.M. 20I3. "Five generations of peace operations: from the "thin blue line" to "painting a country blue". Revista Brasileira de Política Internacional, Rio de Janeiro, 56 (I): I22-I43.

Prunier, G., «Elements pour une histotre du Front Patriotique Rwandais », Politique Africaine. 51: I2I-I38.

Reyntjens, F. I996. "Rwanda: Genocide and Beyond." Journal of Refugee Studies, 9(3): 240-25I.

Roberts, A. I994. “The crisis in UN peacekeeping. IN: Survival: Global Politics and Strategy, London: Routledge, 36(3): 93-120.

Sloan, J. 20II. The Militarisation of Peacekeeping in the Twenty-First Century. Oxford: Hart Publishing.

Waldorf, L. 2009. "Revisiting Hotel Rwanda: genocide ideology, reconciliation, and rescuers." Journal of Genocide Research, London: Routledge, 2009, IOI-I25. 


\section{SITES}

Al Jazeera America. 2013. UN tests combat brigade in Democratic Republic of Congo. >. Acesso em Io de outubro de 20I5: <http://america.aljazeera.com/articles/2013/9/5/un-tests-combat-brigadeindemocraticrepublicofcongo.html

BBC News. 20I5. M23's decline raises hopes of DR Congo peace. Acesso em I3 de outubro de 2015 <http://www.bbc.com/news/world-africa-24802888>

BBC News. 2013 Profile: Bosco Ntaganda the Congolese 'Terminator'. Acesso em I3 de outubro de 2015 < http://www.bbc.com/news/world-africa-I768913I>

International Crisis Group. 2012, Eastern Congo: Why Stabilisation Failed. Acesso em Io de outubro de 2015 <http://www.crisisgroup.org/en/ regions/africa/central-africa/dr-congo/bogI-eastern-congo-why-stabilisation-failed.aspx>.

International Committee Of The Red Cross. 2015. O que é o direito internacional humanitário?. Acesso em: Io de outubro de $2015<$ https://www. icrc.org/por/resources/documents/misc/5tndf7.htm>.

International Rescue Committee. 2007. IRC Study Shows Congo's Neglected Crisis Leaves 5.4 Million Dead; Peace Deal in N. Kivu, Increased Aid Critical to Reducing Death Toll. Acesso em: Io de outubro de $2015<\mathrm{http}: / /$ www.rescue.org/news/irc-study-shows-congos-neglected-crisis-leaves-54-million-dead-peace-deal-n-kivu-increased-aid--433I>.

ONU. 1992. An Agenda for Peace: Preventive diplomacy and related matters. I7 jun. I992. Acesso em: 02 de outubro de $2015<$ http://www.un.org/ documents/ga/res/47/a47rı2o.htm>. ONU, Dag Hammarskjöld Library Research Guides| ONU. Acesso em: I5 de novembro de 2015. $<$ http://research.un.org/en/docs/sc/quick>.

ONU, Middle East - UNEF I |ONU. Acesso em: o2 de outubro de 20I5.<http:// www.un.org/en/peacekeeping/missions/past/unefrbackgr2.html>.

ONU. I999. Report of the Independent Inquiry into the actions of the United Nations during the 1994 genocide in Rwanda. Acesso em I4 de agosto de $2015<$ http://www.un.org/en/ga/search/view_doc.asp?symbol=S/1999/1257>.

ONU. 2000. Report of the Panel on United Nations Peace Operations (Brahimi Report). Acesso em: 02 de outubro de $2015<$ http://www.un.org/en/ ga/search/view_doc.asp?symbol=A/55/305>. 
ONU, 2013. United Nation Operation in the Congo. Acesso em: i3 de dezembro de 20I6.: <http://www.un.org/en/peacekeeping/missions/past/ onuc.htm>.

ONU, 20II. United Nations Operation in Somalia II. Acesso em: i3 de dezembro de 20I6.<http://www.un.org/en/peacekeeping/missions/past/ unosom $2 . h t m>$.

The Guardian. 2007. France's shame?. Acesso em: o9 de dezembro de 2016. $<$ https://www.theguardian.com/world/2007/jan/II/rwanda.insideafrica>

UNIS Vienna, Looking Back/Moving Forward. Acesso em: 30 de setembro de 2015 http://www.unis.unvienna.org/unis/en/GoyearsPK

United Nations Security Council. 2004. Resolution 1565 (2004). UN doc. S/ RES/I565. I out. 2004. Acesso em: 20 de setembro de 2015. <http:// www.un.org/en/ga/search/view_doc.asp?symbol=S/RES/I565 (2004) $>$.

United Nations Security Council. 20I0. Resolution 1925 (2010). UN doc. S/ RES/I925. 28 mai. 20I0. Acesso em: 24 de setembro de $2015<\mathrm{http}: / /$ www.un.org/ga/search/view_doc.asp?symbol=S/RES/I925(2010)>

United Nations Security Council. 20II. Resolution 1991 (2011). UN doc. S/ RES/I99I. 28 jun. 20II. Acesso em: 24 de setembro de 2015. < http:// www.un.org/ga/search/view_doc.asp?symbol=S/RES/I99I(20II)>.

United Nations Security Council._20II. Resolution 2021 (2011). UN doc. S/ RES/202I. 29 nov. 20II. Acesso em: 30 de setembro de 20I5.< http:// www.un.org/ga/search/view_doc.asp?symbol=S/RES/2O2I(20II)>.

United Nations Security Council. 2012. Resolution 2053 (2012). UN doc. S/ RES/2053. 27 jun. 20I2. Acesso em: 4 de outubro de 2015. < http:// www.un.org/ga/search/view_doc.asp?symbol=S/RES/2053(20I2)>.

United Nations Security Council. 20I2. Resolution 2076 (2012). UN doc. S/RES/2076. 20 nov. 2012. : Acesso em: 8 de outubro de 20I5. < http://www.un.org/ga/search/view_doc.asp?symbol=S/ RES/2076+(20I2)\&Lang=E\&utm_source=feedburner\&utm_medium=email\&utm_campaign=Feed\%3A+LatestUnDocuments-SecurityCouncilDocuments+(Latest+UN+documents+-+Security+Council+documents)>.

United Nations Security Council. 20I2. Resolution 2078 (2012). UN doc. S/ RES/2078.28 nov.2012. Acessoem: 8 de outubrode $2015 .<$ http://www. un.org/ga/search/view_doc.asp?symbol=S/RES/2078+(20I2)\&Lan$\mathrm{g}=\mathrm{E} \& u t \mathrm{tm} \_$source=feedburner\&utm_medium=email\&utm_campaig$\mathrm{n}=$ Feed\%3A+LatestUnDocuments-SecurityCouncilDocuments+(La- 
test+UN+documents+-+Security+Council+documents)>.

United Nations Security Council. 2013. Resolution 2098 (2013). UN doc. S/ RES/2098. 28 mar. 20I3. Acesso em: 20 de outubro de $2015 .<$ http:// www.un.org/ga/search/view_doc.asp?symbol=S/RES/2098(2013)>.

United Nations Security Council. 20I4. Resolution 2136 (2014). UN doc. S/ RES/2136. 30 jan. 20I4. Acesso em: 20 de outubro de 20I5. < http:// www.un.org/ga/search/view_doc.asp?symbol=S/RES/2136(2014)>.

United Nations Security Council. 20I4. Resolution 2147 (2014). UN doc. S/RES/2I47. 28 mar. 20I4. Acesso em: 20 de outubro de 2015. $<\quad$ http://www.un.org/en/ga/search/view_doc.asp?symbol=S/ RES/2I47(2OI4)>. United Nations Security Council. Resolution 2211 (20 15). UN doc. S/RES/22II. 26 mar. 20I5. Acesso em: 20 de outubro de 20I5. < http://www.un.org/en/ga/search/view_doc.asp? symbol=S/RES/22II\%2O(20I5)>.

United Nations Security Council. 2013. Special Report of the Secretary-General on the Democratic Republic of the Congo and the Great Lakes region. UN doc. S/2013/757. I7 dez. 2013. Acesso em: 20 de outubro de $2015 .<\quad$ http://www.un.org/en/ga/search/view_doc.asp?symbol=S/2013/757>.

United Nations Security Council. 20I5. Special Report of the Secretary-General on the Democratic Republic of the Congo and the Great Lakes region. UN doc. S/20I5/I72. Acesso em: 20 de outubro de 20I5. < http://www. un.org/ga/search/view_doc.asp?symbol=S/2015/172>.

United Nations Security Council. Peace, Security and Cooperation Framework for the Democratic Republic of the Congo and the region. UN doc. S/20I5/I73. I3 mar. 20I5. Acesso em: 20 de outubro de 20I5. <http:// www.un.org/ga/search/view_doc.asp?symbol=S/2015/I73>

United Nations Security Council. 2015. Special Report of the Secretary-General on the Democratic Republic of the Congo and the Great Lakes region. UN doc. S/20I5/486. Acesso em: 20 de outubro de 20I5. < http://www. un.org/ga/search/view_doc.asp?symbol=S/2015/486>.

United Nations Organization Stabilization Mission In The Drc. MONUSCO Background. Acesso em: 20 out. 2015 <http://www.un.org/en/peacekeeping/missions/monusco/back-ground.shtml>.

SADC. 20I3. Declaration of Commitments by the Movement of March 23 at the Conclusion of the Kampala Dialogue. Acesso em: I7 nov. 2015.http:// www.sadc.int/files/7013/8718/4213/M23_DECLARATION_ENGLSHooor.pdf

World Politics Review. 20I0. DRC Death Toll Debate Raises Questions. Aces- 
so em: Io de outubro de $2015<$ http://www.worldpoliticsreview.com/ articles/5209/war-is-boring-drc-death-toll-debate-raises-questions $>$.

\section{RESUMO}

Desde a criação da primeira missão de peacekeeping até os dias de hoje a ONU busca a adaptação dessas missões para os diferentes contextos que são implementados. Este artigo analisa a possibilidade de uma grande mudança acontecer na forma como as Nações Unidas, por meio do Conselho de Segurança, operam suas Operações de Peacepeeking. Ao apresentar três missões (UNEF I, UNAMIR e MONUSCO) desdobradas em diferentes períodos históricos, identificamos vários elementos em seus mandatos e na forma como foram estabelecidos que indicam uma transformação progressiva no modelo de peacekeeping desde a Guerra Fria - quando os conflitos eram principalmente entre estados - até os dias atuais, quando ocorrem principalmente dentro dos Estados.

\section{PALAVRAS-CHAVE}

Peacekeeping na Africa; Brigada de Intervenção; República Democrática do Congo.

Recebido em 28 de Julho de 2016. Aceito em $1^{\circ}$ de Dezembro de 2016. 